\title{
KARAKTERISTIK KONSUMSI ENERGI BANGUNAN PADA PERMUKIMAN PADAT PENDUDUK DI KOTA MALANG
}

\author{
Suryo Tri Harjanto \\ Dosen Prodi Arsitektur, Fak. Teknik Sipil dan Perencanaan, ITN Malang \\ e-mail: totosuryosaja@gmail.com \\ Putri Herlia Pramitasari \\ Dosen Prodi Arsitektur, Fak. Teknik Sipil dan Perencanaan, ITN Malang \\ e-mail: putri herlia@lecturer.itn.ac.id \\ Bambang Joko Wiji Utomo \\ Dosen Prodi Arsitektur, Fak. Teknik Sipil dan Perencanaan, ITN Malang \\ e-mail: bambangutomo92@gmail.com
}

\begin{abstract}
ABSTRAK
Rumah deret pada permukiman padat penduduk di area bantaran sungai di Kampung Warna-warni Jodipan dan Kampung Muria di Kota Malang memiliki densitas bangunan yang padat. Pengaruh karakteristik spasial bangunan yang belum memenuhi kriteria ramah lingkungan dengan minimnya pencahayaan dan penghawaan alami perlu dikaji lebih lanjut terhadap kinerja termal dan konsumsi energi bangunan. Metode penelitian kuantitatif dilakukan melalui pengambilan data primer dan sekunder untuk selanjutnya dilakukan analisis perbandingan dan korelasi. Hasil akhir penelitian didapatkan bahwa karakteristik spasial bangunan pada rumah deret sangat berpengaruh terhadap kinerja termal dan konsumsi energi bangunan, dimana semakin padatnya densitas bangunan tanpa desain bukaan dan tata ruang yang optimal terhadap pencahayaan dan penghawaan alami, maka kinerja termal bangunan makin tidak memenuhi kriteria nyaman termal. Tingkat konsumsi energi bangunan juga didapatkan hasil bahwa semakin luas tipe bangunan diiringi pula dengan peningkatan kebutuhan operasional listrik, air, dan gas. Hal ini tentu banyak dipengaruhi oleh penghasilan penduduk, gaya hidup, dan jumlah penghuni tiap rumah penduduk.
\end{abstract}

\section{Kata kunci : Konsumsi Energi, Permukian Padat, Kota Malang}

\begin{abstract}
Row houses in densely populated settlements in the riverbank area in Jodipan and Muria Colorful Villages in Malang City have dense building densities. The influence of the spatial characteristics of buildings that do not meet the criteria for environmental friendliness with minimal lighting and natural ventilation needs to be further assessed on the thermal performance and energy consumption of buildings. Quantitative research methods are carried out through primary and secondary data retrieval for comparison and correlation analysis. The final results of the study showed
\end{abstract}


that the spatial characteristics of buildings in a row house greatly affect thermal performance and building energy consumption, where the density of buildings without openings and spatial design is optimal for lighting and natural ventilation, so the thermal performance of buildings does not meet the comfortable thermal. The level of building energy consumption also shows that the wider type of building is accompanied by an increase in the operational needs of electricity, water and gas. This is mostly influenced by the income of the population, lifestyle, and the number of residents in each house.

\section{Keywords : Energy Consumption, Dense Settlements, Malang City}

\section{PENDAHULUAN}

Permukiman padat penduduk di daerah bantaran sungai selama ini tumbuh secara sporadis dan sebagian besar dibangun tanpa mempertimbangkan aspek kelayakan dan kesehatan bangunan. Status kepemilikan lahan yang illegal juga tidak jarang ditemukan pada permukiman ini. Upaya pemerintah dalam merelokasi penduduk untuk tinggal di hunian rumah susun yang lebih layak huni juga membutuhkan proses negosiasi dan sosialisasi yang tidak mudah dan cepat.

Efisiensi energi pada bangunan permukiman padat penduduk juga menjadi perhatian bagi Pemerintah untuk mewujudkan pembangunan berkelanjutan. Pramitasari, P. H. (2018) menjelaskan bahwa rumah deret pada Kampung Warna-warni Jodipan dan Kampung Muria termasuk kawasan permukiman dengan densitas bangunan yang tinggi dan tidak tergolong rumah ramah lingkungan. Tingginya rasio building coverage dan luas lantai bangunan sebesar $100 \%$, serta rendahnya indeks keterbukaan spasial, yaitu $0-26 \%$ tentu berdampak terhadap lingkungan termal kawasan. Hal ini tentu berdampak pula pada efisiensi energi bangunan secara keseluruhan.

Penelitian kali ini mengkaji tentang pengaruh karakteristik spasial bangunan terhadap kinerja termal dan konsumsi energi bangunan pada permukiman padat penduduk bantaran sungai di Kota Malang. Hal ini tentu sangat terkait sebagai strategi Pemerintah dalam mewujudkan pembangunan permukiman padat penduduk secara berkelanjutan.

Optimasi strategi desain bangunan pasif dalam konsep perencanaan dan pembangunan rumah deret kawasan permukiman padat penduduk khususnya di daerah bantaran sungai perlu dibuat agar terwujud rumah deret yang efisien energi. Penduduk dapat tinggal di hunian yang lebih layak dan sehat, dan mengembalikan fungsi RTH (Ruang Terbuka Hijau) pada area bantaran sungai. 


\section{TINJAUAN PUSTAKA}

Efisiensi energi bangunan tidak bisa terlepas dari kriteria pembangunan berkelanjutan. Hoseini, A. H. G., et al. (2013) menjelaskan bahwa pembangunan berkelanjutan sangat terkait dengan aspek energi, baik dilihat dari sumber daya energi hingga limbah yang sangat berpengaruh terhadap peningkatan pembangunan berkelanjutan. Desain berkelanjutan memiliki peran penting untuk mengurangi konsumsi energi bangunan dan mencegah kerusakan lingkungan alam.

Target utama pembangunan berkelanjutan oleh John G, ClementsCroome D, Jeronimidis G. (2005), yaitu efisiensi sumber daya, efisiensi energi (termasuk pengurangan emisi gas greenhouse), pencegahan polusi (termasuk kualitas udara ruang dalam dan pengurangan kebisingan), harmonisasi dengan lingkungan, serta pendekatan terintegrasi dan sistemik.

Omer, A. M. (2013) menjabarkan bahwa energi berkelanjutan adalah prasyarat untuk pembangunan global. Namun, standar kehidupan berbasis energi di negara-negara berkembang berada di bawah standar dari negaranegara maju. Secara keseluruhan, penyebaran teknologi berkelanjutan seperti efisiensi energi dan energi terbarukan untuk memasak, pemanasan, penerangan, peralatan listrik, dan insulasi bangunan di negara-negara berkembang dapat dikatakan lambat.

Total kebutuhan energi bangunan selama masa pakainya dapat dianggap memiliki lima komponen utama (Farinola, 1999) dalam Ciravoglu, A. (2005), yaitu energi yang terkandung dalam konstruksi awal; energi yang dibutuhkan untuk mengoperasikan gedung dalam hal pemanasan, pendinginan, ventilasi, penerangan, tenaga, dan lainnya; energi yang terkandung dalam pemeliharaan rutin dan perbaikan berkala bangunan; energi yang dibutuhkan untuk pembongkaran dan pembuangan bangunan; serta penghematan energi sebagai hasil daur ulang.

Konsumsi energi bangunan terutama digunakan untuk pendinginan, pemanasan, dan pencahayaan (Omer, A. M. 2013). Selain itu, pemilihan bahan dan prinsip desain memiliki dampak yang signifikan (Ciravoglu, A. 2005). Kriteria bangunan yang efisien energi juga harus memenuhi kriteria nyaman termal, dimana temperatur udara kering 24-26 ${ }^{\circ} \mathrm{C}$ dengan kelembaban relatif 50-70\% sesuai SNI 03-6390-2000.

Dengan demikian, diperlukan perancangan desain, penerapan teknologi, manajemen perilaku pengguna, serta pembangunan rumah deret yang diarahkan pada pendekatan konsep efisien energi agar tercapai pembangunan berkelanjutan. 


\section{METODE PENELITIAN}

Metode penelitian kuantitatif dalam penelitian ini dilakukan melalui pengumpulan data primer berupa studi amatan langsung di lapangan, baik wawancara dan kuesioner, serta data sekunder melalui kajian literatur.

Objek studi yang dipilih, yaitu rumah deret umum pada permukiman padat penduduk bantaran sungai bagi masyarakat berpenghasilan rendah. Lokasi penelitian dilakukan pada Kampung Warna-warni Jodipan dan Kampung Muria, Malang. Objek studi pada Kampung Jodipan sebagian besar memiliki orientasi bangunan Utara-Selatan, sementara bangunan pada Kampung Muria sebagian besar berorientasi Barat-Timur.

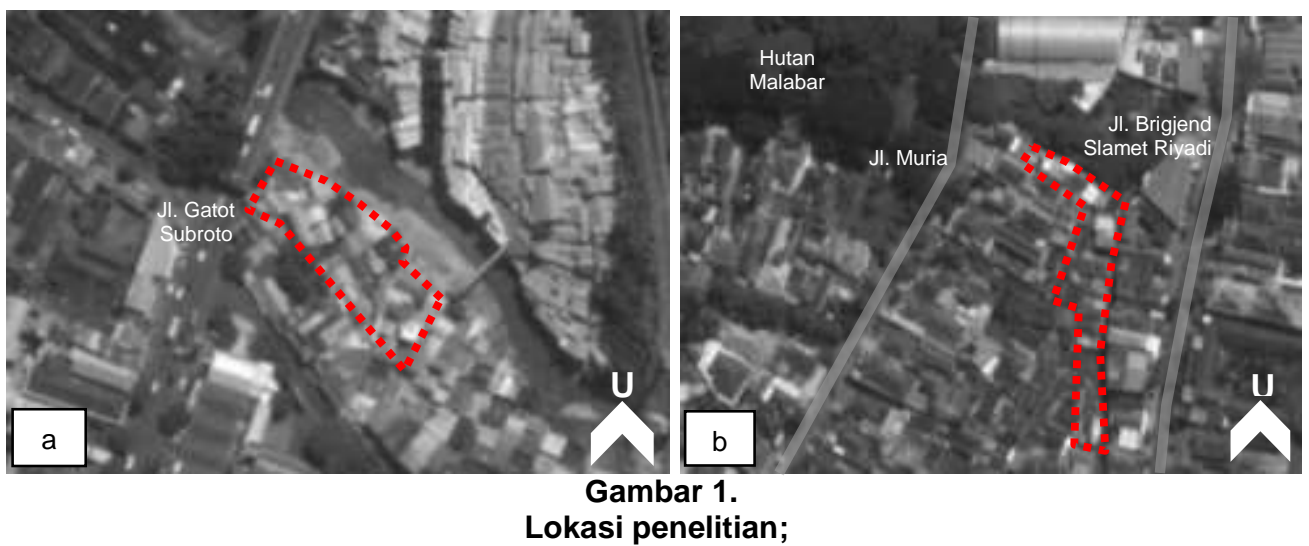

a) Kampung Warna-warni Jodipan, Kelurahan Jodipan, Kecamatan Blimbing, Malang.

b) Kampung Muria, Kelurahan Oro-Oro Dowo, Kecamatan KIojen, Malang

Sumber: Analisis penulis, 2018

\subsection{Teknik Pengumpulan Data}

Pengumpulan data primer diperoleh dari 25-50 rumah tinggal pada tiap objek studi melalui:

a. Observasi lapangan, meliputi penggunaan listrik, air, dan gas; temperatur udara ruang dalam; dan kelembaban relatif udara ruang dalam. Pengukuran kinerja termal menggunakan dry \& wet bulb thermometer.

b. Kuesioner, meliputi data demografi penduduk; lama tinggal, jenis kelamin, usia, hubungan dalam keluarga, etnis, status pernikahan, pekerjaan, pendidikan terakhir, penghasilan tiap bulan, serta waktu tinggal saat weekday dan weekend. Selain itu juga terdapat data bangunan; orientasi bangunan, luas tapak, dan luas bangunan.

c. Wawancara, berupa pola perilaku pengguna. 
Sementara itu, data sekunder juga diperlukan sebagai dokumen pendukung untuk analisis data yang didapat dari artikel ilmiah, baik dari jurnal maupun artikel prosiding, SNI, serta buku teks.

\subsection{Teknik Analisis Data}

Metode analisis perbandingan dan korelasi dijadikan sebagai teknik analisis data untuk mengetahui pengaruh karakteristik spasial bangunan pada tiap tipe bangunan terhadap kinerja termal dan konsumsi energi bangunan pada permukiman padat penduduk bantaran sungai di Kota Malang.

Variabel yang digunakan pada penelitian ini adalah:

a. Variabel bebas; tingkat konsumsi energi listrik, air, dan gas, temperatur udara ruang dalam, dan kelembaban relatif ruang dalam.

b. Variabel terikat; karakteristik spasial bangunan (orientasi bangunan dan tipe rumah deret) dan karakteristik penghuni (usia, tingkat pendidikan, pekerjaan, pendapatan, serta lama tinggal penghuni).

\section{HASIL DAN PEMBAHASAN}

\subsection{Karakteristik Penghuni Rumah Deret}

Sebaran usia penghuni Kampung Warna-warni Jodipan dan Kampung Muria, Malang, yaitu masa balita untuk usia 0-5 tahun, masa anak-anak untuk usia 6-11 tahun, masa remaja untuk usia 12-17 tahun, masa dewasa usia 18-40 tahun, masa tua usia 41-65 tahun, serta masa lanjut usia untuk 65 tahun ke atas.

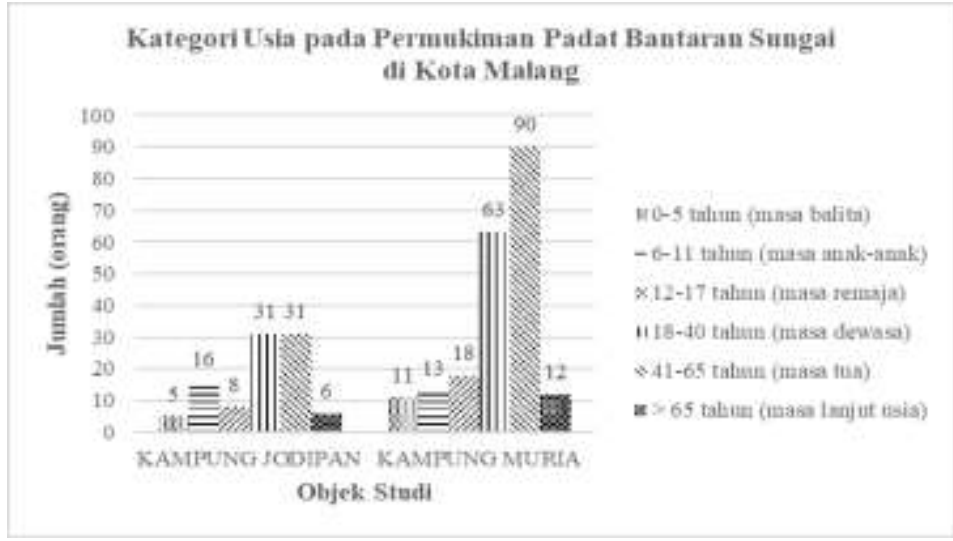

Gambar 2.

Profil Usia Penghuni pada Kampung Jodipan dan Kampung Muria, Malang. Sumber: Analisis penulis, 2018

Gambar 2 menunjukkan bahwa penduduk usia produktif, yaitu 18-40 tahun (dewasa) dan 41-65 tahun (tua) mendominasi pada objek studi 
Kampung Warna-warni Jodipan, Malang. Sedangkan penduduk dengan usia produktif 41-65 tahun banyak mendominasi di Kampung Muria, Malang.

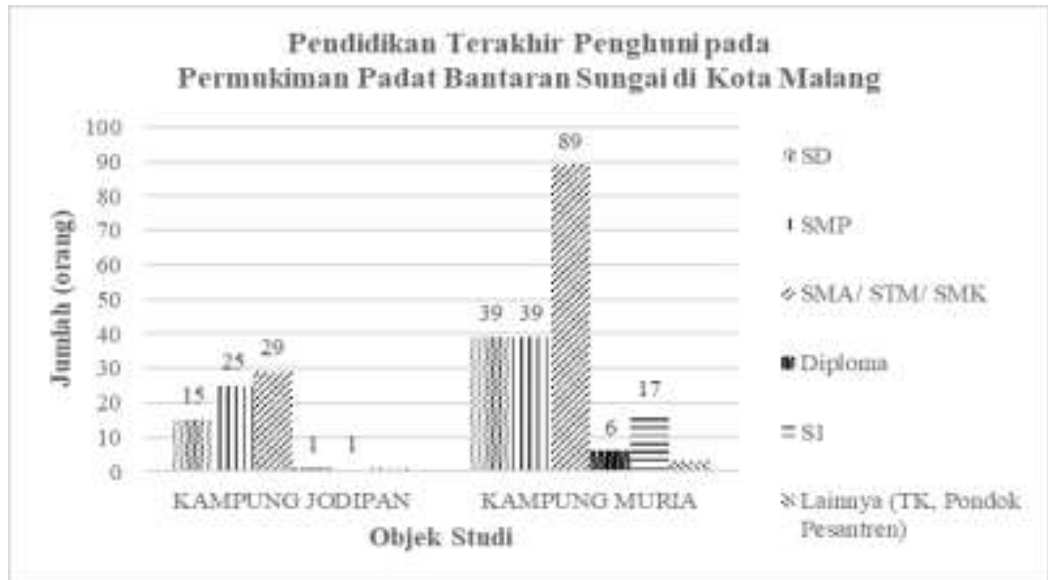

Gambar 3.

Pendidikan Terakhir Penghuni pada Kampung Jodipan dan Kampung Muria, Malang Sumber: Analisis penulis, 2018

Gambar 3 diperoleh kesimpulan bahwa jenjang pendidikan terakhir penduduk Kampung Warna-warni Jodipan dan Kampung Muria, Malang, yaitu SMA/ STM/ SMK. Hal ini menunjukkan bahwa sebagian besar penduduk siap bekerja untuk meningkatkan kesejahteraan keluarga.

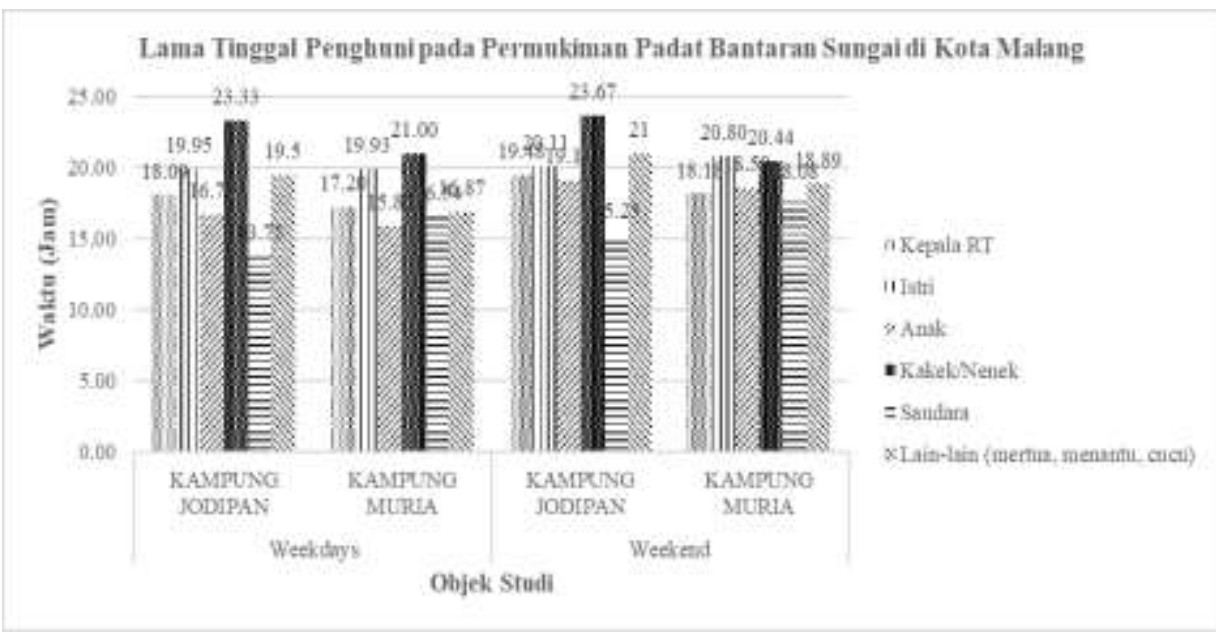

\section{Gambar 4.}

Lama Tinggal Penghuni pada Kampung Jodipan dan Kampung Muria, Malang Sumber: Analisis penulis, 2018

Histogram pada gambar 4 menunjukkan bahwa durasi waktu penduduk pada objek studi memiliki pola yang sama, yaitu kepala keluarga, anak, saudara, mertua, menantu, cucu memiliki waktu tinggal lebih lama

PAWON: Jurnal Arsitektur, Nomor 01 Volume III, Bulan Januari-Juni Tahun 2019, ISSN 2597-7636 
saat akhir pekan (weekend) sekitar 1-1.5 jam untuk kepala keluarga, 2.5-3 jam untuk anak, serta 2 jam untuk saudara, mertua, menantu, cucu. Sementara waktu tinggal para istri dan kakek/nenek tidak memiliki perubahan yang signifikan saat weekdays maupun akhir pekan (weekend) mengingat sebagian besar istri berprofesi sebagai ibu rumah tangga ataupun wirausaha di rumah, sedangkan bagi usia lanjut lebih banyak beraktivitas di rumah sepanjang hari.



Profil Pekerjaan Penghuni pada Kampung Jodipan dan Kampung Muria, Malang Sumber: Analisis penulis, 2018

Histogram yang terdapat pada gambar 5 dapat disimpulkan bahwa wirausaha merupakan profesi utama yang dijadikan pilihan penduduk di wilayah objek studi sebagai sumber penghasilan, baik di Kampung Warnawarni maupun Kampung Muria, Malang.



Gambar 6.

Penghasilan Penghuni pada Kampung Jodipan dan Kampung Muria, Malang Sumber: Analisis penulis, 2018

PAWON: Jurnal Arsitektur, Nomor 01 Volume III, Bulan Januari-Juni Tahun 2019, ISSN 2597-7636 
Rata-rata penghasilan bagi para penghuni Kampung Jodipan sebesar Rp 500.000,00-Rp 2.000.000,00/orang/bulan, sedangkan pada Kampung Muria sebanyak Rp 1.000.000,00-Rp 2.000.000,00/orang/bulan. Nominal penghasilan tersebut dapat dikategorikan rendah dengan rata-rata anggota keluarga sebanyak 3-6 orang tiap rumah.

\subsection{Kinerja Termal Bangunan Rumah Deret}

Pengukuran temperatur udara dan kelembaban relatif udara ruang dalam pada objek studi dilakukan pada empat ruangan yaitu ruang tamu, ruang keluarga, ruang tidur, dan dapur. Pengukuran dilakukan saat kondisi jendela tertutup dan terbuka di setiap ruang untuk selanjutnya dikelompokkan berdasar tipe bangunan; kurang dari $30 \mathrm{~m}^{2}, 30-45 \mathrm{~m}^{2}, 46-60$ $\mathrm{m}^{2}$, dan lebih dari $60 \mathrm{~m}^{2}$.

Gambar 7 menunjukkan bahwa temperatur udara ruang dalam pada objek studi belum memenuhi indikator nyaman termal, dimana rata-rata temperatur udara pada tiap ruang melebihi $26{ }^{\circ} \mathrm{C}$ untuk semua tipe bangunan, baik kondisi jendela terbuka maupun tertutup. Ruang keluarga pada tipe $30 \mathrm{~m}^{2}$ (jendela tertutup) dan lebih dari $60 \mathrm{~m}^{2}$ (jendela terbuka) Kampung Jodipan, serta pada ruang tidur dengan tipe bangunan $30-45 \mathrm{~m}^{2}$ Kampung Muria yang memenuhi kriteria temperatur udara nyaman termal.

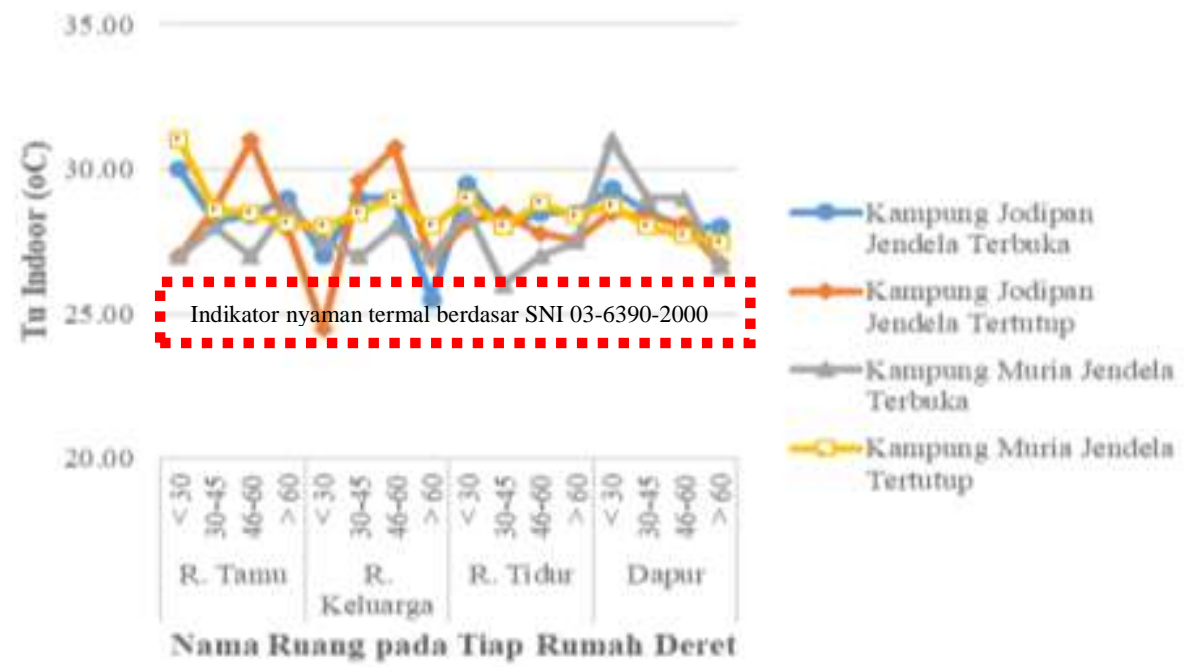

Gambar 7.

Rata-rata Temperatur Udara Ruang Dalam pada

Kampung Warna-warni Jodipan dan Kampung Muria, Malang

Sumber: Analisis penulis, 2018

PAWON: Jurnal Arsitektur, Nomor 01 Volume III, Bulan Januari-Juni Tahun 2019, ISSN 2597-7636 
Kelembaban udara relatif di tiap ruang pada objek studi, baik kondisi jendela terbuka maupun tertutup belum memenuhi indikator kelembaban udara nyaman termal, sebagaimana terlihat pada gambar 8. Rata-rata kelembaban relatif udara di tiap ruang melebihi $70 \%$ pda tiap tipe bangunan. Kelembaban relatif udara pada ruang tidur dengan tipe bangunan $30-45 \mathrm{~m}^{2}$ di Kampung Muria telah memenuhi indikator $\mathrm{RH}$ nyaman termal, dimana berkisar antara 68-69.75\% saat kondisi jendela terbuka dan tertutup.

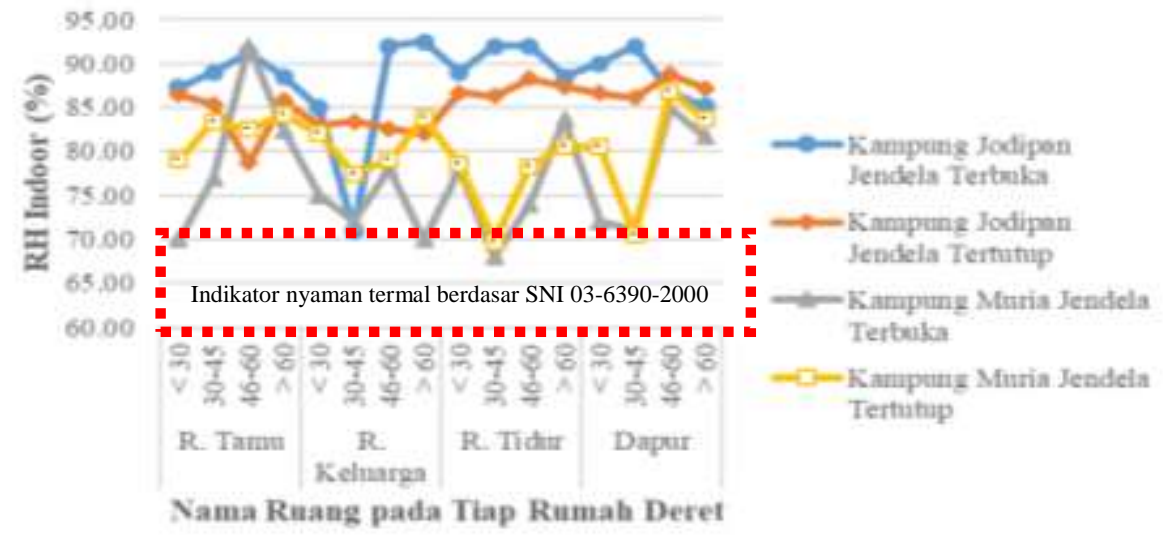

Gambar 8.

Rata-rata Kelembaban Relatif Udara Ruang Dalam pada Kampung Warna-warni Jodipan dan Kampung Muria, Malang Sumber: Analisis penulis, 2018

Tingginya densitas bangunan tanpa adanya perencanaan desain yang efisien energi pada permukiman objek studi berakibat kinerja lingkungan termal pada ruang amatan (ruang tamu, ruang keluarga, ruang tidur, dan dapur) pada semua tipe bangunan belum memenuhi indikator nyaman termal, dimana temperatur udara ruang dalam melebihi $26{ }^{\circ} \mathrm{C}$ dengan kelembaban relatif udara melebihi $70 \%$, baik kondisi jendela terbuka maupun tertutup. Hal ini menunjukkan bahwa rumah tinggal penduduk pada tiap objek studi dapat dikatakan panas dan lembab.

\subsection{Konsumsi Energi Bangunan Rumah Deret}

Konsumsi energi listrik dapat dilihat pada gambar 9 bahwa semakin besar tipe bangunan diiringi pula dengan peningkatan konsumsi energi listrik. Biaya operasional listrik pada tipe bangunan 30-45 $\mathrm{m}^{2}$ Kampung Jodipan lebih tinggi dibanding Kampung Muria dengan tipe bangunan yang sama, dan paling tinggi diantara semua tipe banguna pada Kampung Jodipan sendiri. Hal ini dapat disebabkan adanya jumlah anggota keluarga maupun peralatan listrik yang digunakan pada tiap rumah. Semakin banyak jumlah anggota keluarga dan peralatan listrik yang digunakan pada tiap tipe

PAWON: Jurnal Arsitektur, Nomor 01 Volume III, Bulan Januari-Juni Tahun 2019, ISSN 2597-7636 
bangunan maka makin tinggi pula jumlah daya dan biaya operasional listrik tiap bulan. Sementara pada Kampung Muria biaya operasional listrik paling tinggi pada tipe bangunan lebih dari $60 \mathrm{~m}^{2}$.

Penggunaan air bersih pada kedua objek studi sebagaimana terlihat pada gambar 9 dapat dinyatakan bahwa biaya operasional air bersih semakin meningkat seiring dengan makin luasnya tipe bangunan.

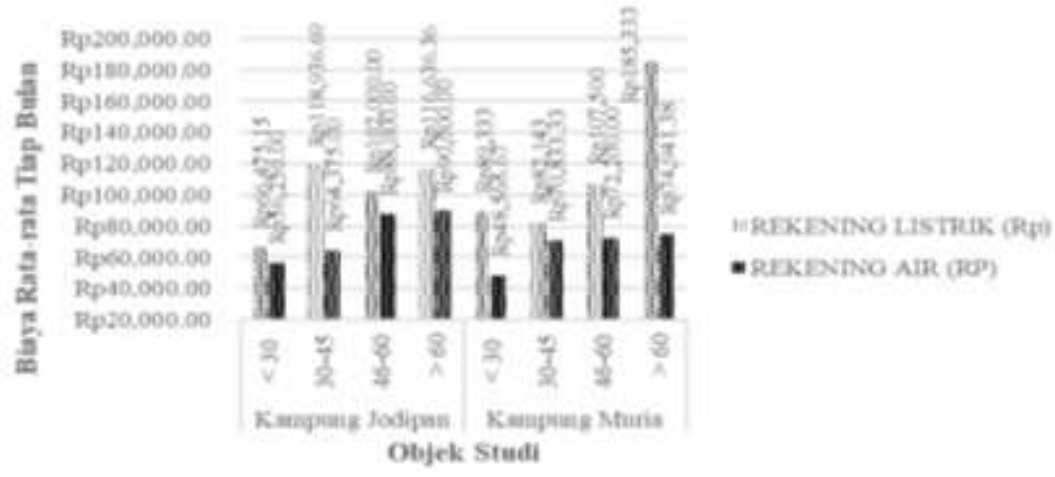

Gambar 9.

Biaya Rata-rata Operasional Listrik dan Air Tiap Bulan pada Kampung Warna-warni Jodipan dan Kampung Muria, Malang Sumber: Analisis penulis, 2018

Kebutuhan air bersih pada gambar 10 menunjukkan adanya peningkatan jumlah pemakaian air pada tiap tipe bangunan, dimana semakin besar luasan lantai bangunan, maka jumlah pemakaian air juga makin meningkat. Kebutuhan galon air minum juga sangat minim, dimana penggunaan jumlah galon kurang dari $1 \mathrm{~m}^{3}$ pada semua tipe bangunan pada kedua objek studi dan semakin besar luasan lantai bangunan maka jumlah galon air minum yang dibutuhkan semakin besar, bergantung pada jumlah anggota keluarga tiap rumah.

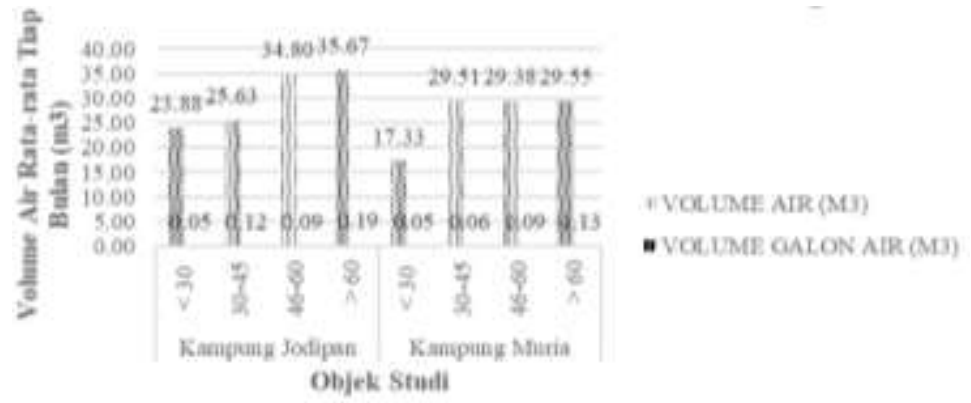

Gambar 10.

Kebutuhan Air Bersih dan Galon Air Minum Rata-rata Tiap Bulan pada Kampung Warna-warni Jodipan dan Kampung Muria, Malang

Sumber: Analisis penulis, 2018 
Kebutuhan gas pada kedua objek studi dapat ditunjukkan pada gambar 11 bahwa semakin luas lantai bangunan, maka jumlah volume gas yang dibutuhkan makin banyak pula, bergantung pula dengan jumlah anggota keluarga dan perilaku penghuni tiap rumah. Semakin banyak anggota keluarga tiap tipe bangunan, makin besar pula kebutuhan volume gas tiap rumah.

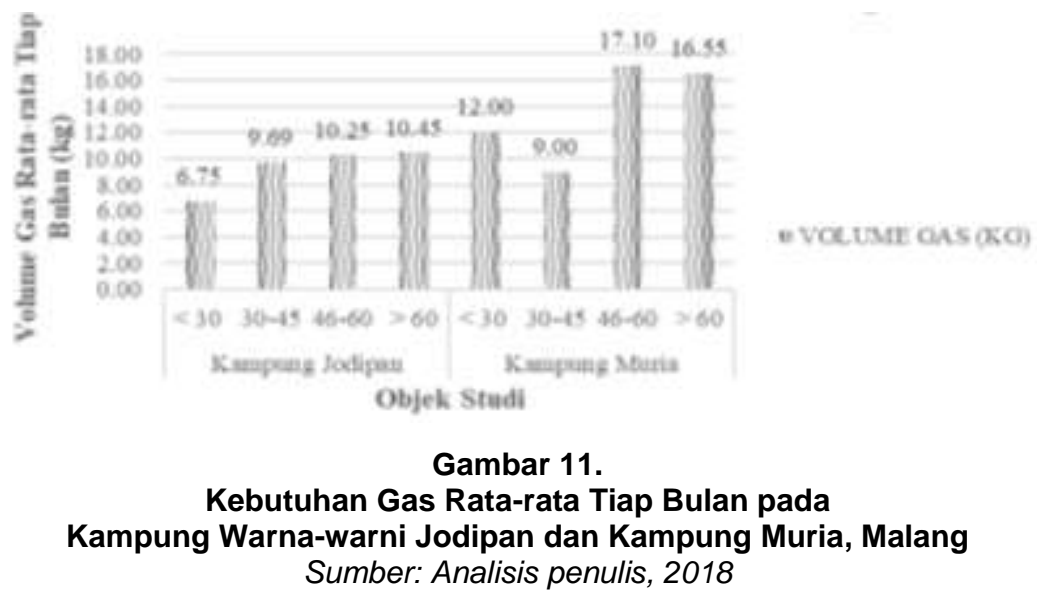

Konsumsi energi listrik, air, dan gas pada kedua objek studi sangat dipengaruhi oleh karakteristik pengguna, karakteristik bangunan, dan pola perilaku pengguna.

\section{KESIMPULAN}

Karakteristik spasial bangunan dilihat dari orientasi dan tipe bangunan dan karakteristik pengguna (usia, pendidikan, pekerjaan, penghasilan, dan lama tinggal penghuni tiap hari, jumlah anggota keluarga tiap rumah) sangat berpengaruh terhadap pola perilaku pengguna yang berdampak terhadap kinerja termal dan konsumsi energi bangunan.

Orientasi bangunan, baik yang menghadap Utara-Selatan maupun Barat-Timur turut berpengaruh terhadap kinerja termal dan konsumsi energi bangunan pada objek studi terlebih banyak rumah yang terbayangi akibat kepadatan bangunan yang tinggi.

Semakin tinggi densitas bangunan pada permukiman padat, dimana luasan lantai dasar bangunan $100 \%$ dengan indeks keterbukaan spasial kurang dari $30 \%$ tanpa diiringi perencanaan desain efisien energi berakibat pada penurunan kinerja termal ruang, baik temperatur udara $\left(\mathrm{TU} 26^{\circ} \mathrm{C}\right)$ dan kelembaban relatif udara $(\mathrm{RH} 70 \%)$ menjadi semakin panas dan lembab karena tidak memenuhi kriteria nyaman termal. 
Konsumsi energi bangunan, baik operasional energi listrik, air, dan gas juga semakin meningkat seiring dengan bertambahnya luasan lantai bangunan, jumlah anggota keluarga tiap rumah, lama tinggal penghuni tiap hari, dan pola perilaku pengguna dalam pemanfaatan peralatan listrik.

Oleh karena itu diperlukan strategi perencanaan desain untuk permukiman pada khususnya daerah bantaran sungai yang efisien energi dan memenuhi kriteria pembangunan berkelanjutan.

\section{DAFTAR PUSTAKA}

Ciravoglu, A. (2005) : A Research On Embodied Energy of Building Materials: Reflections On Turkey. The 2005 World Sustainable Building Conference. 01-131: 910-917.

Hoseini, A. H. G., et al. (2013) : Sustainable Energy Performances of Green Buildings: A Review of Current Theories, Implementations and Challenges. Renewable and Sustainable Energy Reviews. 25: 1-17.

John G, Clements-Croome D, Jeronimidis G. (2005) : Sustainable Building Solutions: A Review of Lessons From The Natural World. Building and Environment 2005. 40:319-28.

Omer, A. M. (2013) : Renewable Energy Technologies and Sustainable Development. African Journal Of Engineering Research. Vol. 1(4): 102-116.

Pramitasari, P. H. (2018) : Karakteristik Spasial Bangunan pada Permukiman Padat Penduduk di Kota Malang Objek Studi: Kampung Warna-Warni Jodipan dan Kampung Muria, Kota Malang. Prosiding Seminar Nasional Infrastruktur Berkelanjutan 2018: 269-274.

SNI 03-6389-2000. Konservasi Energi Selubung Bangunan pada Bangunan Gedung. 